\title{
O Preconceito Sexual Internalizado por Homossexuais Masculinos
}

\author{
Adriana Nunan \\ Bernardo Jablonski \\ Terezinha Féres-Carneiro \\ Pontifícia Universidade Católica do Rio de Janeiro
}

\begin{abstract}
RESUMO
Apesar do surgimento, nas últimas décadas, de uma vasta gama de estudos relacionados à homossexualidade, pouco foi produzido sobre o tema do preconceito internalizado. Tendo como base uma articulação entre conceitos oriundos da psicologia social e da psicanálise, procede-se neste trabalho, a partir da literatura existente, a uma investigação sobre o preconceito sexual internalizado, definido como a aceitação pelos indivíduos homossexuais das atitudes negativas veiculadas pela sociedade em relação à homossexualidade. Tal aceitação resulta em sentimentos negativos sobre si mesmo - principalmente culpa e vergonha de ser ou de experienciar desejo homossexual. Busca-se relacionar o preconceito sexual internalizado com suas principais manifestações clínicas, assim como com alguns dos mecanismos de defesa utilizados pelos homossexuais masculinos, a saber: a negação, a formação reativa, a racionalização e o encobrimento. Ao cabo do trabalho, levantam-se algumas questões relacionadas à redução do preconceito internalizado.
\end{abstract}

Palavras-chave: preconceito internalizado; homossexualidade masculina; manifestações clínicas.

\begin{abstract}
Internalized Prejudice in Male Homosexuals

Despite the emergence, in the last decades, of a wide range of studies related to homosexuality, little has been produced on the subject of internalized prejudice. Based on an articulation between social psychology and psychoanalytical concepts, as well as existing literature on the subject, this article investigates internalized prejudice, defined as an acceptance by homosexuals of society's negative attitudes regarding homosexuality. Such an acceptance, results in negative feelings towards oneself mainly shame and guilt of being gay or of experiencing same-sex desire. We strive to relate internalized prejudice with its major clinical manifestations, as well as some of the defense mechanisms used by male homosexuals (denial, reactive formation, rationalization and passing). $\mathrm{We}$ conclude the article by raising some issues concerning the reduction of internalized prejudice.
\end{abstract}

Keywords: internalized prejudice; male homosexuality; clinical manifestations.

Indivíduos estigmatizados estão frequentemente expostos a ameaças diretas e indiretas a sua autoestima. Estereótipos de que os homossexuais são inferiores, que possuem defeitos de caráter moral, são mantidos tanto por instituições sociais (tais como família, escola, Igreja e Estado) como pelos meios de comunicação de massa em geral (Nunan, 2003). São imagens tão difundidas que se torna difícil deixar de internalizá-las em algum grau, sobretudo durante a infância (Pereira \& Leal, 2002). Homossexuais que internalizam estas crenças podem se sentir inferiores aos heterossexuais e incapazes de alcançar objetivos que contradigam o preconceito.
Os eventos de vida negativos decorrentes do preconceito institucionalizado e da discriminação podem ser chamados de "estressores externos", enquanto que os "estressores internos" seriam aqueles ligados ao preconceito internalizado (Lipp, 2001). Em outras palavras, pode-se dizer que quando o estereótipo é muito forte ou pernicioso, membros do grupo alvo tendem a aceitá-lo e incorporá-lo à sua autoimagem, fazendo com que sentimentos negativos com relação à própria orientação sexual sejam generalizados para o self como um todo, aqui entendido como o si-próprio, ou seja, como a totalidade do eu, e não como uma instância psíquica (Laplanche \& Pontalis, 1985). Este 
processo se assemelha ao proposto por Allport (1979/1954) sobre os traços devidos à estigmatização, segundo o qual indivíduos estigmatizados apresentam reações defensivas, como reflexo do preconceito experienciado na sociedade. Estes mecanismos podem ser "extrovertidos" (uma preocupação obsessiva com características ou comportamentos que possam revelar a homossexualidade), ou "introvertidos" (incluindo ódio contra si mesmo e identificação com o agressor). Postulamos, junto com Williamson (2000), que os mecanismos considerados "introvertidos" podem ser equacionados com as teorias correntes sobre preconceito internalizado (Friedman \& Downey, 1995; Igartua, Gill \& Montoro, 2003).

A ideia de que homossexuais poderiam internalizar o preconceito existente na sociedade surgiu na década de 70 (Weinberg, 1972), ganhando força a partir do início da década de 80 , com a criação, por Malyon (1982), do conceito de "homofobia internalizada". Apesar dos termos "preconceito sexual internalizado" e "homofobia internalizada" aparecerem como sinônimos na literatura especializada, utilizaremos apenas o primeiro termo, pois discordamos do conceito de homofobia ${ }^{1}$. Ressaltamos, igualmente, que alguns autores (Russell \& Bohan, 2006) criticam a ideia de preconceito internalizado por acreditarem que esta repatologiza os homossexuais e que nosso foco de atenção deve estar voltado para a desconstrução do preconceito institucionalizado, isto é, aquele presente na sociedade mais ampla. Não obstante, em consonância com a noção de que o preconceito contra homossexuais deva ser combatido, postulamos que isso não invalida o fato de que muitos indivíduos internalizam este preconceito, e que os sintomas clínicos correlacionados com esta dinâmica devam ser levados em conta quando abordados em psicoterapia. Vale lembrar também que o preconceito internalizado, como conceito mais amplo, está presente entre membros de outros grupos estigmatizados (tais como os negros, por exemplo), que têm seu autoconceito prejudicado pela internalização do preconceito e de sentimentos associados com a discriminação. A seguir, procuraremos avançar nesta questão levantando alguns pontos que julgamos pertinentes ao tema, tais como sua conceituação, modos de aferição, manifestação clínica e, finalmente, possíveis modos de redução. Ressaltamos, também, que o presente artigo articula conceitos oriundos da psicanálise e da psicologia social.

\section{Preconceito sexual internalizado}

O preconceito sexual internalizado pode ser definido sucintamente como a "aceitação pelos indivíduos homossexuais das atitudes negativas veiculadas pela sociedade em relação à homossexualidade" (Antunes \& Machado, 2005, p. 8). Esta aceitação resultaria em "sentimentos negativos sobre o self - principalmente culpa e vergonha de ser gay ou lésbica ou de experienciar desejo homossexual" (Downey \& Friedman, 1995 , p. 435$)^{2}$. Em outras palavras, o sujeito passa a acreditar que o self é inerentemente mau, sem valor ou repulsivo, e de que boa parte de seus problemas pessoais decorrem disto. De um modo geral, o preconceito internalizado se apresenta em um contínuo que vai desde questionamentos sobre seu próprio valor como indivíduo até o ódio por si mesmo, estando correlacionado também com depressão, baixa autoestima, vergonha, culpa, medo, desconfiança, insegurança, ansiedade, queixas psicossomáticas, sentimentos de solidão, frustração, isolamento social, dificuldade de estabelecer e manter relacionamentos amorosos, violência doméstica, comportamento sexual de risco, abuso de álcool e drogas, transtornos alimentares, e comportamento ou ideação suicida (Atkins, 1998; Dew \& Chaney, 2005; Herek, Cogan, Gillis \& Glunt, 1997; Lehman, 1997; McKirnan \& Peterson, 1989; Nunan, 2004; Reece, 1988; Shidlo, 1994). Dificulta, igualmente, a assunção da homossexualidade e, no caso de sofrerem algum tipo de discriminação, estes indivíduos tendem a colocar a culpa em si mesmos (pois acreditam que mereceram o castigo), o que diminui ainda mais sua autoestima (Malyon, 1982; Sophie, 1987). "Muitas lésbicas, gays e, bissexuais sentem que o próprio centro do seu ser é maculado, inaceitável. (...) A surpresa é que alguém sobreviva a esta situação." (Finnegan \& McNally, 2002, p. 92-93) ${ }^{3}$.

De acordo com vários autores (Allen \& Oleson, 1999), a internalização do preconceito é um evento experienciado, em diversos graus, por quase todos os homossexuais criados em sociedades ocidentais. Não obstante o número razoavelmente grande de estudos que tratam deste tema, existe uma escassez significativa de pesquisas no que se refere à prevalência do preconceito internalizado entre homossexuais. Shidlo (1994), por exemplo, aponta para os inúmeros problemas metodológicos das poucas pesquisas existentes, aliado ao fato de que grande parte destes dados foram coletados na década de 70 e, portanto, em um período histórico anterior às conquistas do movimento homossexual e ao advento da aids, eventos que marcaram profundamente a experiência de ser homossexual 
na nossa sociedade. Mas, de acordo com alguns estudos (Jay \& Young, 1977), em torno de 30\% dos homossexuais poderiam ter atitudes ou sentimentos negativos com relação à própria homossexualidade em algum momento de suas vidas.

\section{Aferição e desenvolvimento do preconceito internalizado}

A partir da década de 70 também existiram tentativas de criar escalas, inventários ou questionários que fossem capazes de medir o preconceito internalizado com um grau razoável de precisão (Cook, 1994; Martin \& Dean, 1987; Nungesser, 1983). De acordo com Shidlo (1994), em que pese alguns problemas metodológicos, a escala com melhor operacionalização e validade é a NHAI (Nungesser Homosexual Attitudes Inventory), criada por Nungesser (1983). Deste modo, Shidlo (1994) dedicou-se a elaborar uma versão atualizada da NHAI, simultaneamente criando uma escala distinta, mas complementar, intitulada AIDS-Related Internalized Homonegativity ou ARIH, com o intuito de investigar crenças ligadas à aids que não faziam parte do instrumento original de Nungesser (1983). Utilizando estas duas escalas, Shidlo (1994) encontrou correlações entre preconceito internalizado e sintomas tais como depressão, doenças psicossomáticas, baixa autoestima, sentimentos de falta de estabilidade do self, desconfiança e solidão. O autor postula, também, que indivíduos que recebem pouco suporte socioemocional de outros homossexuais tendem a apresentar graus mais elevados de preconceito internalizado.

Posteriormente, outras escalas foram desenvolvidas (Currie, Cunningham \& Findlay, 2004; Mayfield, 2001; Ross \& Rosser, 1996) ${ }^{4}$. Não obstante os esforços despendidos, uma análise detalhada destes novos instrumentos revela a persistência de uma série de problemas metodológicos que precisam ser sanados antes que estas escalas possam ser usadas para mensurar, confiavelmente, o preconceito internalizado em homossexuais. Primeiramente, devido à estigmatização, muitos sujeitos, ao preencherem estes instrumentos, não revelam sua verdadeira orientação sexual ou mentem sobre aspectos relacionados a ela, mesmo quando as respostas são anônimas. Em segundo lugar, os critérios para definir o que é ser homossexual variam conforme a escala. Por exemplo: aceita-se para efeitos sociais que homossexual é o indivíduo que se relaciona com membros de seu mesmo sexo biológico. Em algumas escalas, no entanto, também são considerados homossexuais indivíduos que tiveram uma única experiência homossexual durante toda a vida ou que têm apenas fantasias homossexuais. Por outro lado, muitos homens que se consideram heterossexuais já tiveram uma ou mais experiências homossexuais. Desta forma, a homossexualidade pode ser definida tanto pelo comportamento sexual do sujeito, pelos seus sentimentos de atração com relação a pessoas do mesmo sexo biológico ou por autoidentificação (o sujeito se vê como homossexual). Assim, podemos dizer que estes instrumentos acabam sendo prejudicados, dentre outros motivos, pela falta de rigor dos termos científicos empregados (Bhat, Leigh \& Wardlow, 1996; Badgett \& King, 1997). Além disso, tanto nos Estados Unidos como no Brasil, não existem pesquisas ou dados demográficos oficiais sobre a população homossexual, o que faz com que as informações disponíveis sobre estes indivíduos sejam incompletas, no que diz respeito à caracterização das mesmas.

De acordo com Finnegan e McNally (2002), o preconceito internalizado se inicia muito cedo na vida dos homossexuais, que são expostos desde crianças (assim como o resto da sociedade) aos valores preconceituosos presentes na cultura. Segundo Herek (1994) e Wood (1990), por exemplo, na sociedade ocidental a maioria das pessoas é consistentemente ensinada a ver a homossexualidade como sendo algo pecaminoso ou moralmente errado, a considerá-la antinatural e a reagir com repulsa diante desta orientação sexual. Em outras palavras, podemos dizer que antes mesmo que o indivíduo se dê conta de qualquer diferença sexual ele já teria aprendido os perigos associados a uma não heterossexualidade (Malyon, 1982; Pecheny, 2004). Gradualmente, o sujeito aprenderia estes valores, de forma a internalizá-los e os aceitando como verdades, incorporadas ao seu autoconceito 5 .

Postulamos, junto com outros autores (Allen \& Oleson, 1999; Svensson, 2003), que uma das características centrais do preconceito internalizado é o sentimento de vergonha (tanto individual, quanto grupal), e o consequente desejo de se esconder, experienciado pelos homossexuais. A vergonha pode ser definida como "aquele sentimento de autocastigo que surge quando estamos convencidos de que existe algo em nós mesmos que é errado, inferior, falho, fraco ou sujo." (Morrison, 1998, p. 103) ${ }^{6}$. Assim, a vergonha é fundamentalmente um sentimento de desprezo contra nós mesmos, uma visão negativa do nosso self filtrada através dos nossos próprios olhos. Geralmente esta visão seria autoconsciente e acompanhada pela convicção de que falhamos em algo importante, o que por sua vez geraria um desejo de encobrimento.

De um modo geral, acreditamos que o sentimento de vergonha pode ser introjetado pelo indivíduo (caso no qual ele se tornará um componente central do pre- 
conceito internalizado), ou pode se transformar em raiva e violência, direcionadas, em forma de retaliação, à sociedade mais ampla. Seja qual for a situação, a vergonha deve ser psicoterapeuticamente trabalhada (eliminada ou, ao menos, atenuada) para que o sujeito possa eventualmente assumir a própria orientação sexual e integrar este aspecto da sua identidade a sua vida como um todo (Barret \& Barzan, 1996). Não obstante, muitos indivíduos reagem vivendo de acordo com os valores homo/bi/transfóbicos e heterossexistas da sociedade. Assim, não é incomum para homossexuais, bissexuais e transgêneros acreditar que heterossexuais são superiores e homossexuais inferiores (Finnegan \& McNally, 2002, p. 93) ${ }^{7}$.

Segundo as autoras acima, o sujeito lida com estas crenças negativas de várias formas distintas. Alguns homossexuais vivem como se fossem heterossexuais, porque assumir sua orientação sexual significaria ter que lidar com a ideia de que eles são indivíduos de segunda categoria, imorais e inaceitáveis para a sociedade, para suas famílias e para si mesmos. A pesquisa realizada por Allen e Oleson (1999), verificou, por exemplo, que os seguintes estereótipos estavam associados com o sentimento de vergonha entre homossexuais e, consequentemente, com preconceito internalizado: pervertido, efeminado, fraco, doente, defeituoso, passivo e pouco masculino.

\section{Defesas psíquicas e manifestações clínicas}

Para Finnegan e McNally (2002), homossexuais com preconceito internalizado tendem a utilizar uma série de defesas psíquicas para lidar com seu conflito interior e com a ansiedade crônica decorrente, sendo as mais comuns: negação, formação reativa, racionalização e encobrimento, como veremos, mesmo que brevemente, a seguir.

A negação pode ser considerada uma das defesas psíquicas mais poderosas, sobretudo no caso de homossexuais com preconceito internalizado. Sucintamente, a negação pode ser definida como um "mecanismo de defesa em que aos fatos ou implicações lógicas da realidade externa é negado reconhecimento, em favor de fantasias internas de concretização de meros desejos" (Cabral \& Nick, 2003, p. 205). Em outras palavras, é essencialmente um processo através do qual o sujeito inconscientemente modifica a realidade para que esta se adapte às suas necessidades. De fato, o indivíduo que faz uso desta defesa cria uma realidade subjetiva particular, na medida em que distorce ou muda fatos e eventos da realidade objetiva (isto é, a que é compartilhada pelas pessoas ao seu redor). Desta forma, o sujeito é capaz de ignorar uma informação percebida como uma ameaça para sua autoestima. Para muitas pessoas, apenas contemplar a possibilidade de que ela possa se sentir atraída por outras do mesmo sexo é tão perigoso e aterrorizante que a negação é a única saída psíquica que ela encontra para lidar com estes sentimentos inaceitáveis.

Ainda de acordo com Finnegan e McNally (1992), indivíduos que internalizam estereótipos negativos com relação à homossexualidade podem realizar uma cisão em suas vidas, tendo relacionamentos homo e heterossexuais simultaneamente. Em outras palavras, mesmo que se comportem homossexualmente, se veem como heterossexuais. Muitos se casam com o objetivo de negar sua orientação sexual ou de se assegurarem que, de fato, sentem-se atraídos pelo sexo oposto. Vale lembrar que este tipo de atitude é bastante diferente daquela adotada por bi ou homossexuais que levam uma vida dupla: uma coisa é não querer se assumir, outra completamente distinta é não conseguir sequer admitir para si mesmo a própria homossexualidade. Outro caminho adotado por indivíduos com preconceito internalizado é o religioso, isto é, o sujeito pode acreditar que estará a salvo de seus desejos homossexuais se viver uma vida de celibato ou de serviço a Deus. Seja qual for o caminho escolhido, grande parte das atitudes adotadas para lidar com o preconceito internalizado tende a potencializar os sentimentos de vergonha, ódio ou culpa.

A formação reativa (ou formação de reação) "consiste na adoção de um padrão de comportamento que é diretamente o oposto da tendência reativa que a pessoa está tentando esconder, negar ou refutar" (Cabral $\&$ Nick, 2003, p. 122). Neste sentido, pode ser considerada uma defesa poderosa por meio da qual o sujeito se defende daquilo que ele tem medo de ser identificando-se, agindo ou se transformando no oposto. Indivíduos que usam este mecanismo com frequência se identificam com o agressor e se transformam nele, isto é, em alguém que ataca determinadas características ou grupos de pessoas (Friedman, 1998). Como exemplo, podemos citar indivíduos que, com medo de serem homossexuais, se unem a certos grupos sociais (religiosos, conservadores ou preconceituosos de um modo geral) e passam a condenar, publicamente, a homossexualidade. Neste caso, o ódio a si mesmo seria desviado para o próprio grupo. Outros comportamentos mais sutis também podem ser indícios de formação reativa em homossexuais com preconceito internalizado, como, por exemplo, contar um número excessivo de piadas anti-homossexuais ou adotar um comportamento exagerado e estereotipicamente con- 
siderado masculino - no sentido de corroborar características associadas à força, determinação, independência, objetividade, impositividade sexual, agressividade e autoritarismo, entre outras (Vandello e cols, 2008; Wang, Jablonski \& Magalhães, 2006).

A racionalização é o processo pelo qual o indivíduo procura apresentar uma explicação coerente do ponto de vista lógico, ou aceitável do ponto de vista moral, para uma atitude, uma ação, uma ideia ou um sentimento de cujos motivos verdadeiros não se apercebe (Laplanche \& Pontalis, 1985, p. 543). No caso de homossexuais com preconceito internalizado, racionalizações incluiriam ideias do tipo: "Eu só fiz aquilo porque estava bêbado/drogado.", "Não é minha culpa. Fui seduzido.", "Estava curioso. Tenho uma mente aberta e estou disposto a experimentar de tudo.", "É uma fase." ou "Não há necessidade de falar sobre minha vida pessoal.".

De acordo com Finnegan e McNally (2002), o encobrimento (mecanismo através do qual o sujeito esconde informações sobre sua verdadeira identidade, recebendo e aceitando um tratamento baseado em falsas suposições a seu respeito) é uma estratégia utilizada por grande parte dos homossexuais durante algum período de suas vidas, geralmente enquanto ainda não são capazes de assumir sua orientação sexual. No caso dos homossexuais masculinos, exemplos comuns de encobrimento seriam os de levar amigas para eventos familiares (com a intenção de que estas pareçam ser suas namoradas), referir-se a namorados utilizando termos neutros tais como "pessoa" (por exemplo, "conheci uma pessoa ontem"), evitar falar sobre sua vida pessoal, tentar se vestir, falar e agir sem gestos ou maneirismos que possam indicar uma possível homossexualidade, evitar contatos com outros indivíduos que da mesma forma pareçam homossexuais, forçar-se a ter um grande número de relacionamentos heterossexuais ou até mesmo casar-se e/ou ter filhos com uma mulher. Para homossexuais com preconceito internalizado, no entanto, o encobrimento faz parte de uma defesa psíquica inflexível e diária, sem a qual o sujeito não consegue lidar com sua orientação sexual. Ao contrário das demais defesas, o encobrimento é uma escolha consciente, apesar de que, para alguns indivíduos, é possível que ela acabe se tornando uma resposta automática devido à elevada frequência com que é utilizada. Neste sentido, acreditamos que o encobrimento pode se tornar destrutivo caso o sujeito não consiga abandonar a máscara de heterossexual, mesmo quando cercado por outros indivíduos similarmente estigmatizados. Em consequência, estes homossexuais podem passar a vida procurando esconder sua orientação sexual.
Além das defesas psíquicas descritas acima (baseadas em Finnegan \& McNally, 2002), uma outra comumente utilizada por indivíduos com preconceito internalizado é a "supercompensação" (Malyon, 1982; Pharr, 1988). Neste sentido, alguns homossexuais tentariam superar o preconceito buscando sempre atingir um nível econômico, social e cultural superior ao da maior parte da população. Já Margolies, Becker e Jackson-Brewer (1987) sugerem que abertamente rejeitar ou ter preconceito contra heterossexuais, assim como apresentar um "orgulho excessivo" em ser homossexual também podem ser indícios de preconceito internalizado.

O preconceito sexual internalizado aparece com mais frequência em indivíduos não assumidos, adolescentes (exacerbado pelas descobertas sexuais e mudanças características desta fase da vida), idosos (devido ao fato de terem passado a maior parte de suas vidas em uma sociedade onde a homossexualidade era bem menos aceita ou tinha pouca visibilidade), religiosos (posto que a maioria das religiões condena a homossexualidade), viúvos (a morte de um parceiro pode trazer à tona antigos sentimentos de preconceito internalizado, visto que tende a ser interpretada pelo viúvo como uma punição por seu comportamento homossexual), mas pode existir em pessoas que revelaram e aparentemente aceitam sua sexualidade, tornando-se um fator relevante para sua saúde mental durante o resto de suas vidas (Downey \& Friedman, 1995; Shernoff, 1999; Svensson, 2003). Alguns estudos (Rowen \& Malcolm, 2002) postulam, igualmente, que o preconceito internalizado parece estar mais relacionado com uma rejeição social antecipada ou percebida do que com episódios concretos de discriminação, o que sugere que determinadas variáveis psíquicas individuais atuam como mediadoras importantes neste processo. Não obstante a relevância do tema, as pesquisas acima citadas não mencionam quais variáveis seriam estas. Acreditamos, portanto, que este tema mereça estudos mais aprofundados no futuro.

No que se refere especificamente à questão da aids, podemos dizer que, no caso de homossexuais HIVpositivo com preconceito internalizado, a contaminação é vista como uma punição e pode ser acompanhada de sentimentos de culpa (Nicholson \& Long, 1990). Dupras (1994) menciona que estes indivíduos apresentam uma série de dificuldades de ajustamento sexual, no sentido de que o sexo representaria duas transgressões simultâneas: a homossexualidade e o vírus HIV. Um aspecto ainda mais preocupante é a relação do preconceito internalizado com um maior risco de infecção pelo vírus HIV: muitos destes indi- 
víduos não se identificam como homossexuais nem participam de eventos dentro da comunidade homossexual. É possível que isso os deixe menos expostos a materiais educativos sobre práticas de sexo seguro, tornando-os mais propensos a adotar comportamentos de risco (Finnegan \& McNally, 2002).

\section{Reduzindo o preconceito sexual internalizado}

Segundo diversos autores (Downey \& Friedman, 1995; Friedman, 1998), a assunção da homossexualidade está intimamente relacionada com a diminuição do preconceito internalizado. Em outras palavras, na medida em que o preconceito diminui, o sujeito se sente mais livre para assumir sua orientação sexual, ao passo em que a visibilidade também tende a diminuir o preconceito internalizado. Assim, a assunção da homossexualidade provoca o questionamento das crenças e normas sociais, enquanto que o preconceito sexual (tanto institucionalizado quanto internalizado) é progressivamente exposto e rotulado como um problema. Em vez de odiar-se a si mesmo o indivíduo passa, a partir deste momento, a dirigir seu descontentamento para alvos externos, isto é, para as instituições sociais que favorecem o preconceito (Margolies, Becker \& Jackson-Brewer, 1987). De acordo com Kus (1988), também é necessário que o sujeito reconheça os sentimentos de raiva e rejeição anteriormente direcionados ao self, trabalhando-os individualmente (utilizando biblioterapia ${ }^{8}$, por exemplo) ou através de uma psicoterapia adequada, isto é, realizada por um profissional que esteja familiarizado com os estudos mais recentes ligados à homossexualidade, incluindo a questão do preconceito internalizado.

Além de assumir-se como homossexual, entrar em contato com indivíduos similarmente estigmatizados e frequentar grupos militantes ou de apoio-mútuo, também tende a reduzir o preconceito internalizado, favorecendo uma melhoria na qualidade de vida (Kus, 1988). De acordo com Sophie (1987), ter amigos homossexuais que atuem como modelos positivos e que contradigam estereótipos é extremamente importante na superação do preconceito internalizado e na assunção da homossexualidade. No entanto, esta necessidade de contato com outros homossexuais coloca o indivíduo em uma situação paradoxal: para poder mudar suas crenças negativas a respeito da homossexualidade, o sujeito precisa ativamente procurar interagir com pessoas que ele considera indesejáveis. Segundo a autora, na maioria dos casos este paradoxo é solucionado quando o indivíduo acaba entrando em contato, seja forçosamente ou por acaso, com membros da comunidade homossexual.
Ainda segundo Sophie (1987), a redução (ou eliminação) do preconceito internalizado pode ser observada através de determinados indícios, tais como o fato do indivíduo se sentir mais confortável com relação a seus sentimentos, relacionamentos e fantasias homossexuais; sua aceitação, admiração e respeito por outros homossexuais; sua habilidade em estabelecer uma relação amorosa homossexual significativa; assunções da própria homossexualidade realizadas de forma positiva (ao invés de agressivamente ou como se o sujeito estivesse pedindo desculpas); e o pertencimento a um grupo de referência positivo com relação à homossexualidade (grupo este que pode incluir tanto outros homossexuais quanto amigos heterossexuais não preconceituosos).

Segundo alguns autores (Downey \& Friedman, 1995; Margolies e cols., 1987), é bastante incomum que homossexuais procurem psicoterapia apresentando como queixa principal o preconceito internalizado: este frequentemente aparece na forma de sintomas e em conjunção com uma série de outras queixas, tais como dificuldades com relacionamentos, trabalho ou sentimentos de depressão e/ou ansiedade sem causa aparente. Em alguns casos, é possível que o indivíduo esteja consciente de sentimentos negativos relacionados à homossexualidade, mas tem dificuldade em perceber as formas em que estas crenças podem estar afetando sua vida no presente. De acordo com alguns estudos (Lease, Cogdal \& Smith, 1995), homossexuais com preconceito internalizado que estão em terapia podem ter dificuldade em investigar temas relacionados à sexualidade, além de apresentarem uma redução no grau de compromisso com o processo terapêutico.

Por último, gostaríamos de lembrar que segundo os estudos citados ao longo deste trabalho, o preconceito sexual internalizado entre homossexuais masculinos parece estar particularmente correlacionado com sintomas, dificuldades ou sofrimentos, geralmente precipitados por um evento de vida estressante, tais como: busca por terapias de conversão da homossexualidade, depressão e suicídio, transtornos alimentares, abuso de álcool e drogas, comportamentos sexuais de risco, e violência doméstica. Frisamos, não obstante, que o fato de a literatura especializada ter encontrado correlações entre preconceito internalizado e determinados sintomas não quer dizer que esta relação seja causal, direta ou que se estabeleça, invariavelmente, em todos os casos. O que postulamos é que, no caso de homossexuais que apresentam determinadas queixas clínicas, a influência do preconceito internalizado deve ser sempre avaliada como uma possibilidade. 


\section{REFERÊNCIAS}

Alexander, R. A. (1986). The relationship between internalized homophobia and depression and low self-esteem in gay men. Tese de doutorado não-publicada, University of California at Santa Barbara.

Allen, D. J., \& Oleson, T. (1999). Shame and internalized homophobia in gay men. Journal of Homosexuality, 37(3), 33-43.

Allport, G. W. (1979). The nature of prejudice. Reading, MA: Addison-Wesley. (Original publicado em 1954)

Amadio, D. M. (2006). Internalized heterosexism, alcohol use, and alcohol-related problems among lesbians and gay men. Addictive Behaviors, 31, 1153-1162.

Antunes, R., \& Machado, C. (2005). Dupla invisibilidade: A violência nas relações homossexuais. Psychologica, 39, 167-187.

Atkins, D. (1998). (In)visible bodies: Weight and appearance in a lesbian, bisexual and gay community. Dissertação de mestrado não-publicada, University of Iowa.

Barret, R., \& Barzan, R. (1996). Spiritual experiences of gay men and lesbians. Counseling and Values, 41, 4-15.

Badgett, L., \& King, M. C. (1997). Lesbian and gay occupational strategies. Em A. Gluckman \& B. Reed (Orgs.), Homo economics: Capitalism, community, and lesbian and gay life (pp. 73-86). London: Routledge.

Bhat, S., Leigh, T. W., \& Wardlow, D. L. (1996). The effect of homosexual imagery in advertising on attitude toward the ad. Em D. L. Wardlow (Org.), Gays, lesbians, and consumer behavior: Theory, practice, and research issues in marketing (pp. 161-176). New York: Harrington Park Press.

Cabral, A., \& Nick, E. (2003). Dicionário técnico de psicologia. São Paulo: Cultrix.

Cook, D. R. (1994). Internalized Shame Scale: Professional manual. Wisconsin: Channel Press.

Currie, M. R., Cunningham, E. G., \& Findlay, B. (2004). The short internalized homonegativity scale: Examination of the factorial structure of a new measure of internalized homophobia. Educational and Psychological Measurement, 64(6), 1053-1067.

Dew, B. J., \& Chaney, M. P. (2005). The relationship among sexual compulsivity, internalized homophobia, and HIV at-risk sexual behavior in gay and bisexual male users of internet chat rooms. Sexual Addiction \& Compulsivity, 12(4), 259-273.

Downey, J. I., \& Friedman, R. C. (1995). Internalized homophobia in lesbian relationships. Journal of the American Academy of Psychoanalysis, 23(3), 435-447.

Dupras, A. (1994). Internalized homophobia and psychosexual adjustment among gay men. Psychological Reports, 75, 23-28.

Finnegan, D. G., \& McNally, E. B. (2002). Counseling lesbian, gay, bisexual, and transgender substance abusers - Dual identities. New York: Haworth Press.

Friedman, R. C. (1998). Internalized homophobia, pathological grief, and high-risk sexual behavior in a gay man with multiple psychiatric disorders. Journal of Sex Education and Therapy, 23(2), 115-120.

Friedman, R. C., \& Downey, J. I. (1995). Internalized homophobia and the negative therapeutic reaction. Journal of the American Academy of Psychoanalysis, 23(1), 99-113.

Herek, G. M. (1994). Assessing attitudes towards lesbians and gay men: A review of empirical research with the ATLG scale. Em B. Greene \& G. M. Herek (Orgs.), Lesbian and gay psychology: Theory, research, and clinical applications (pp. 149-169). Thousand Oaks, CA: Sage.
Herek, G. M., Cogan, J. C., Gillis, J. R., \& Glunt, E. K. (1997). Correlates of internalized homophobia in a community sample of lesbians and gay men. Journal of the Gay and Lesbian Medical Association, 2, 17-25.

Igartua, K. J., Gill, K., \& Montoro, R. (2003). Internalized homophobia: A factor in depression, anxiety, and suicide in the gay and lesbian population. Canadian Journal of Community Mental Health, 22(2), 15-30.

Jay, K., \& Young, A. (1977). The gay report. New York: Summit.

Kus, R. J. (1988). Alcoholism and non-acceptance of gay self: The critical link. Journal of Homosexuality, 15(1-2), 25-41.

Laplanche, J., \& Pontalis, J-B. (1985). Vocabulário de psicanálise. São Paulo: Martins Fontes.

Lease, S. H., Cogdal, P. A., \& Smith, D. (1995). Counseling expectancies related to counselor's sexual orientation and clients' internalized homophobia. Journal of Gay \& Lesbian Psychotherapy, 2(3), 51-65.

Lehman, M. (1997). At the end of the rainbow: A report on gay male domestic violence and abuse. Retirado em 15 de outubro de 2010, de http://www.mincava.umn.edu/documents/rainbow /At\%20The\%20End\%200f\%20The\%20Rainbow.pdf

Lipp, M. E. N. (2001). Estresse emocional: A contribuição de estressores internos e externos. Revista de Psiquiatria Clínica, 28, 347-349.

Malyon, A. K. (1982). Psychotherapeutic implications of internalized homophobia in gay men. Journal of Homosexuality, 7, 59-69.

Margolies, L., Becker, M., \& Jackson-Brewer, K. (1987). Internalized homophobia: Identifying and treating the oppressor within. Em Boston Lesbian Psychologies Collective (Org.), Lesbian psychologies - Explorations and challenges (pp. 229-241). Chicago: University of Illinois Press.

Martin, J. L., \& Dean, L. L. (1987). Ego-dystonic homosexuality scale. Manuscrito não-publicado, School of Public Health, Columbia University.

Mayfield, W. (2001). The development of an internalized homonegativity inventory for gay men. Journal of Homosexuality, 41(2), 53-76.

McKirnan, D. J., \& Peterson, P. L. (1989). Alcohol and drug use among homosexual men and women: Epidemiology and population characteristics. Addictive Behavior, 14, 545-553.

Morrison, A. P. (1998). The culture of shame. London: Jason Aronson.

Nicholson, W. D., \& Long, B. C. (1990). Self-esteem, social support, internalized homophobia, and coping strategies of HIV+ gay men. Journal of Consulting and Clinical Psychology, 58, 873-876.

Nunan, A. (2001). A questão da identidade homossexual e sua influência nos padrões de consumo. Dissertação de mestrado não-publicada, Pontifícia Universidade Católica do Rio de Janeiro, Rio de Janeiro.

Nunan, A. (2003). Homossexualidade: Do preconceito aos padrões de consumo. Rio de Janeiro: Caravansarai.

Nunan, A. (2004). Violência doméstica entre casais homossexuais: O segundo armário? PSICO, 35, 69-78.

Nungesser, L. G. (1983). Homosexual acts, actors, and identities. New York: Praeger.

Pecheny, M. (2004). Identidades discretas. Em L. F. Rios, V. Almeida, R. Parker, C. Pimenta \& V. Terto Jr. (Orgs.), Homossexualidade: Produção cultural, cidadania e saúde (pp. 16-33). Rio de Janeiro: ABIA. 
Pereira, H., \& Leal, I. (2002). A homofobia internalizada e os comportamentos para a saúde numa amostra de homens homossexuais. Análise Psicológica, 1, 107-113.

Pharr, S. (1988). Homophobia: A weapon of sexism. Little Rock, AR: Chardon.

Reece, R. (1988). Causes and treatment of sexual desire discrepancies in male couples. Em E. Coleman (Org.), Psychotherapy with homosexual men and women: Integrated identity for clinical practice (pp. 149-166). New York: Haworth Press.

Ross, M. W., \& Rosser, B. S. (1996). Measurement and correlates of internalized homophobia: A factor analytic study. Journal of Clinical Psychology, 52(1), 15-21.

Rowen, C. J., \& Malcolm, J. P. (2002). Correlates of internalized homophobia and homosexual identity formation in a sample of gay men. Journal of Homosexuality, 43(2), 77-92.

Russell, G. M., \& Bohan, J. S. (2006). The case of internalized homophobia. Theory \& Psychology, 16(3), 343-366.

Shernoff, M. (1999). Gay widowers: Life after the death of a partner. New York: Haworth Press.

Shidlo, A. (1994). Internalized homophobia: Conceptual and empirical issues in measurement. Em B. Greene \& G. M. Herek (Orgs.), Lesbian and gay psychology: Theory, research, and clinical applications (pp. 176-205). California: Sage.
Sophie, J. (1987). Internalized homophobia and lesbian identity. Journal of Homosexuality, 14, 53-65.

Svensson, T. K. (2003). Bioethical analysis of sexual reorientation interventions - The ethics of conversion therapy. Florida: Brown Walker Press.

Szymanski, D. M., \& Chung, Y. B. (2001). The lesbian internalized homophobia scale: A rational/theoretical approach. Journal of Homosexuality, 41(2), 37-52.

Vandello, J. A., Bosson, J. K., Cohen, D., Burnaford, R. M., \& Weaver, J. R. (2008). Precarious manhood. Journal of Personality and Social Psychology, 95(6), 1325-1339.

Wang, M-L., Jablonski, B., \& Magalhães, A. S. (2006). Identidades masculinas: Limites e possibilidades. Psicologia em Revista, $12,54-65$.

Weinberg, G. (1972). Society and the healthy homosexual. New York: Anchor Books.

Williamson, I. (2000). Internalized homophobia and health issues affecting lesbians and gay men. Health Education Research, 15, 97-107.

Wood, F. W. (1990). An American profile: Opinions and behavior, 1972-1989. Detroit: Gale Research.

Recebido: 12/09/2008

Última revisão: 13/07/2010

Aceite final: 20/07/2010

\section{Notas:}

1 De acordo com o que postulamos em Nunan (2001), a palavra "homofobia" sugere que o preconceito contra homossexuais pode ser melhor entendido como uma forma de psicopatologia (fobia) individual, ignorando os aspectos sociais do fenômeno. Vale lembrar também que pesquisas recentes (Amadio, 2006) têm utilizado cada vez mais o conceito de "heterossexismo internalizado" como um sinônimo para "preconceito internalizado".

2 Tradução nossa.

3 Tradução nossa.

4 Neste mesmo período, foi desenvolvida a The Lesbian Internalized Homophobia Scale ou LIHS (Szymanski \& Chung, 2001), criada especificamente para medir o preconceito internalizado entre lésbicas.

5 Não devemos assumir, no entanto, que todos os homossexuais sejam afetados da mesma forma ou com a mesma intensidade pelas influências culturais descritas aqui. Tal como postula Malyon: "O significado desenvolvimentista de qualquer aspecto particular da experiência de socialização é determinado pelas vulnerabilidades especiais, necessidades e estratégias defensivas de cada indivíduo" (1982, pp. 61-62).

6 Tradução nossa.

7 Tradução nossa.

8 A "biblioterapia" pode ser definida como uma técnica que utiliza a leitura dirigida com fins terapêuticos, ocupacionais ou educativos.

\section{Sobre os autores:}

Adriana Nunan: Psicóloga, Doutora em Psicologia Clínica pela Pontifícia Universidade Católica do Rio de Janeiro.

Bernardo Jablonski: Psicólogo, Doutor em Psicologia pela Fundação Getúlio Vargas - Rio de Janeiro. Professor Assistente da Pontifícia Universidade Católica do Rio de Janeiro.

Terezinha Féres-Carneiro: Psicóloga, Doutora em Psicologia (Psicologia Clínica) pela Pontifícia Universidade Católica de São Paulo (1981), Pós-Doutorada pela Universidade de Paris V (1988), professora titular da Pontifícia Universidade Católica do Rio de Janeiro.

Endereço para correspondência: Bernardo Jablonski - Rua Marquês de São Vicente, 287/701 - Gávea - 22451-041 Rio de Janeiro/RJ. Endereço eletrônico: bjablonski@uol.com.br. 